\title{
The determinants and longitudinal changes in vitamin $D$ status in middle-age: a Northern Finland Birth Cohort 1966 study
}

\author{
Helmi Ikonen ${ }^{1}$ (1) · Johanna Lumme ${ }^{2,3,4} \cdot$ Jussi Seppälä ${ }^{1,5,13} \cdot$ Paula Pesonen $^{6} \cdot$ Terhi Piltonen $^{2,3,4}$. \\ Marjo-Riitta Järvelin 1,7,8,9 Karl-Heinz Herzig ${ }^{3,10,11}$. Jouko Miettunen ${ }^{1,3} \cdot$ Maarit Niinimäki $^{2,3,4}$. \\ Saranya Palaniswamy ${ }^{1,7} \cdot$ Sylvain Sebert ${ }^{1} \cdot$ Marja Ojaniemi ${ }^{2,3,12}$
}

Received: 23 November 2020 / Accepted: 2 June 2021 / Published online: 17 June 2021

(c) The Author(s) 2021

\begin{abstract}
Purpose Populations living in the Nordic countries are at high risk for vitamin D (VitD) deficiency or insufficiency. To reduce the risk, nationwide interventions based on food fortification and supplementation are being implemented. However, there is limited evidence about the impact of such public health campaigns on target populations.

Methods We studied an unselected sample of 3650 participants (56.2\% females) from the longitudinal Northern Finland Birth Cohort 1966 with repeated measures of serum 25-hydroxyvitamin D [25(OH)D] at ages 31 (1997) and 46 (2012-2013). Timepoints corresponded to the period before and during the food fortification. We examined the effect of VitD intake from the diet and supplementation, body mass index and previous $25(\mathrm{OH}) \mathrm{D}$ concentration on $25(\mathrm{OH}) \mathrm{D}$ concentration at 46 years using a multivariable linear regression analysis. A 25(OH)D $z$ score adjusted for sex, season, latitude and technical effect was used in the analysis.

Results We observed an increase of $10.6 \mathrm{nmol} / \mathrm{L}$ in $25(\mathrm{OH}) \mathrm{D}$, when the baseline $25(\mathrm{OH}) \mathrm{D}$ was $54.3 \mathrm{nmol} / \mathrm{L}$. The prevalence of serum $25(\mathrm{OH}) \mathrm{D}$ below $<50 \mathrm{nmol} / \mathrm{L}$ was halved. The changes were found for both sexes and were more pronounced in winter compared to summer months. Regular VitD supplementation had a significant positive effect on $25(\mathrm{OH}) \mathrm{D}$ at the age of 46 , as well as had the dietary intake of fortified dairy products and fish, and the previous $25(\mathrm{OH}) \mathrm{D}$ concentration. However, the intake of fat-spreads albeit VitD-fortified, did not predict 25(OH)D.

Conclusion Our results demonstrated the positive impact of the fortification programme on VitD status in middle-aged population.
\end{abstract}

Keywords 25-hydroxyvitamin D $\cdot 25(\mathrm{OH}) \mathrm{D} \cdot$ Food fortification · Vitamin D fortification · Vitamin D supplementation . Population-based

\section{Introduction}

In addition to the traditional role of vitamin D (VitD) in bone health, several studies have shown an inverse association between serum 25-hydroxyvitamin D [25(OH)D] and multiple non-skeletal medical conditions, including type 2

Helmi Ikonen and Johanna Lumme contributed equally. Sylvain Sebert and Marja Ojaniemi contributed equally.

\footnotetext{
Marjo-Riitta Järvelin

m.jarvelin@imperial.ac.uk

Sylvain Sebert

sylvain.sebert@oulu.fi
}

Extended author information available on the last page of the article diabetes [1], cardiovascular diseases [2,3], autoimmune diseases [4], certain cancers [5], depression [6], and all-cause mortality [7-9]. This might be important to acknowledge in the middle-aged population, where we observe steep increase in the prevalence of non-communicable diseases.

In the northern latitudes, where the daylight is reduced for a long winter period, the dietary intake of VitD-rich foods and oral supplementation are essential sources of VitD to prevent VitD deficiency [10, 11]. Unfortunately, only a few natural food products (fish, egg yolk, and certain wild mushrooms) contain significant amounts of VitD [12]. To ensure an adequate VitD status, assessed by serum $25(\mathrm{OH}) \mathrm{D}$, among the population, some Nordic countries (Finland, Sweden, and Norway) have launched VitD food fortification programmes 
by adding VitD systematically to non-organic dairy products, fat spreads, breakfast cereals, and certain baby foods [13, 14].

In December 2002, the National Nutrition Council (NNC) of Finland has granted approval for (i) all fluid dairy products (excluding organic) and respective plant-based alternatives to be systematically fortified with $0.5 \mu \mathrm{g} / 100 \mathrm{~g}$ and (ii) all fat spreads, excluding butter, to be systematically fortified with $10 \mu \mathrm{g} / 100 \mathrm{~g}$ with vitamin $\mathrm{D}_{3}$ [15]. The first evaluation of this programme has shown that the prevalence of serum $25(\mathrm{OH}) \mathrm{D}$ concentrations below $50 \mathrm{nmol} / \mathrm{L}$ were still observed in $21.3 \%$ of the population [16], and the recommendation was, therefore, doubled in the second fortification wave in 2010 [15]. In addition to fortification, the NNC recommends individual oral supplementation with $10 \mu \mathrm{g} /$ day of vitamin $\mathrm{D}_{3}$ during the darkest time of the year for adults not regularly consuming fish and food products fortified with VitD (i.e., dairy products or fat spreads) [17].

A study by Jääskeläinen et al. [18] reported an average improvement of $17 \mathrm{nmol} / \mathrm{L}$ in serum $25(\mathrm{OH}) \mathrm{D}$ concentrations [18]. The study samples were from the Finnish national health survey Health2000 and 2011-2012 (among participants over 30 years, $n=6134$ in 2000 and 4051 in 2012, mean age $=56$ years) conducted before and after the fortification waves [18]. However, studies from Sweden and Norway conflicted with this observation $[19,20]$. They reported a relatively stable VitD status among the general population in recent decades despite the start of VitD fortification programmes (Online resource 1) [19, 20]. The Norwegian study also observed a moderate correlation between VitD status in 1994 and 2008, suggesting tracking of serum 25(OH)D and, thus, the stability of VitD status over the years [20].

There is a paucity of studies to address the possible independent effect of VitD fortification programmes on the VitD status in the general population taking into account a variety of additional risk factors, including amongst other BMI, VitD intake from other dietary sources and supplementation as well as previous VitD status. Therefore, the objective of the present study was to evaluate this question using longitudinal data in a population-based birth cohort from Northern Finland sampled before and during the national food fortification. We aimed at analyzing whether the effect of fortification was independent from the effect of supplementation. Our study population consists of adults followed from young adulthood until middleage and is characterized by an increasing incidence of chronic diseases and females reaching menopausal age. We consider this group interesting in the light of VitD status and from a public health perspective, as representing a relevant target for preventive actions.

\section{Subjects and methods}

\section{Study population}

The study population was derived from a prospective, general population-based birth cohort, the Northern Finland Birth Cohort 1966 (NFBC1966). This cohort has been described in detail elsewhere [21,22], including two studies about VitD [23, 24]. In this study, we included the cohort participants who attended both the 31-year (1997) and 46-year (2012-2013) clinical follow-ups, before and during NNC launched food fortification programme (Fig. 1). At both timepoints, data from postal questionnaires and clinical examinations, including blood samples, were obtained.

The measure of serum $25(\mathrm{OH}) \mathrm{D}$ concentrations was available from a total of 5,571 participants $(51.9 \%$ females) at 31 years and 5,659 (55.8\% females) at 46 years (Fig. 1). We excluded the participants with the outlier values using the first quartile cutoff $-1.5 \times \mathrm{IQR}$ for the lower limit and the third quartile cutoff $+1.5 \times \mathrm{IQR}$ for the upper limit) [25]. A total of 112 measurements were considered outliers. At 31 years all 53 measurements were from the upper end. At 46 years, 75 out of 76 measurements were from the upper end (Online resource 2). In the analysis, we retained those participants with available $25(\mathrm{OH}) \mathrm{D}$ measurements at both timepoints $(n=3650)$. To identify possible selection bias, we examined the VitD status and the characteristics of the total population (i.e., VitD available at either timepoint) and the retained samples (i.e., VitD available at 31 years and 46 years). We found no differences in the vitD status or descriptive characteristics between full sample and those with the repeated measures (Online resource 3).

To define VitD status, we used serum 25(OH)D cutoffs of 30,50 , and $75 \mathrm{nmol} / \mathrm{L}$ for the VitD status groups based on both the IOM and ES guidelines [26, 27].

\section{Serum 25(OH)D measurements at 31 and 46 years}

During the clinical examination visits at 31 and 46 years of age, blood samples, which were preceded by an overnight fast, were drawn between 8 and $11 \mathrm{am}$. The samples were frozen at $-70{ }^{\circ} \mathrm{C}$ until analyzed. At 31 years, the participants' serum concentrations of $25(\mathrm{OH}) \mathrm{D}$ were determined using liquid chromatography-tandem mass spectrometry (LC-MS/MS; Elstree, Hertfordshire, UK). This detailed procedure has been described previously [23, 28]. A subset of the blood samples was later analysed with a chemiluminescence microparticle immunoassay (CMIA) Architect i2000SR automatic analyzer (Abbott Diagnostics). This 


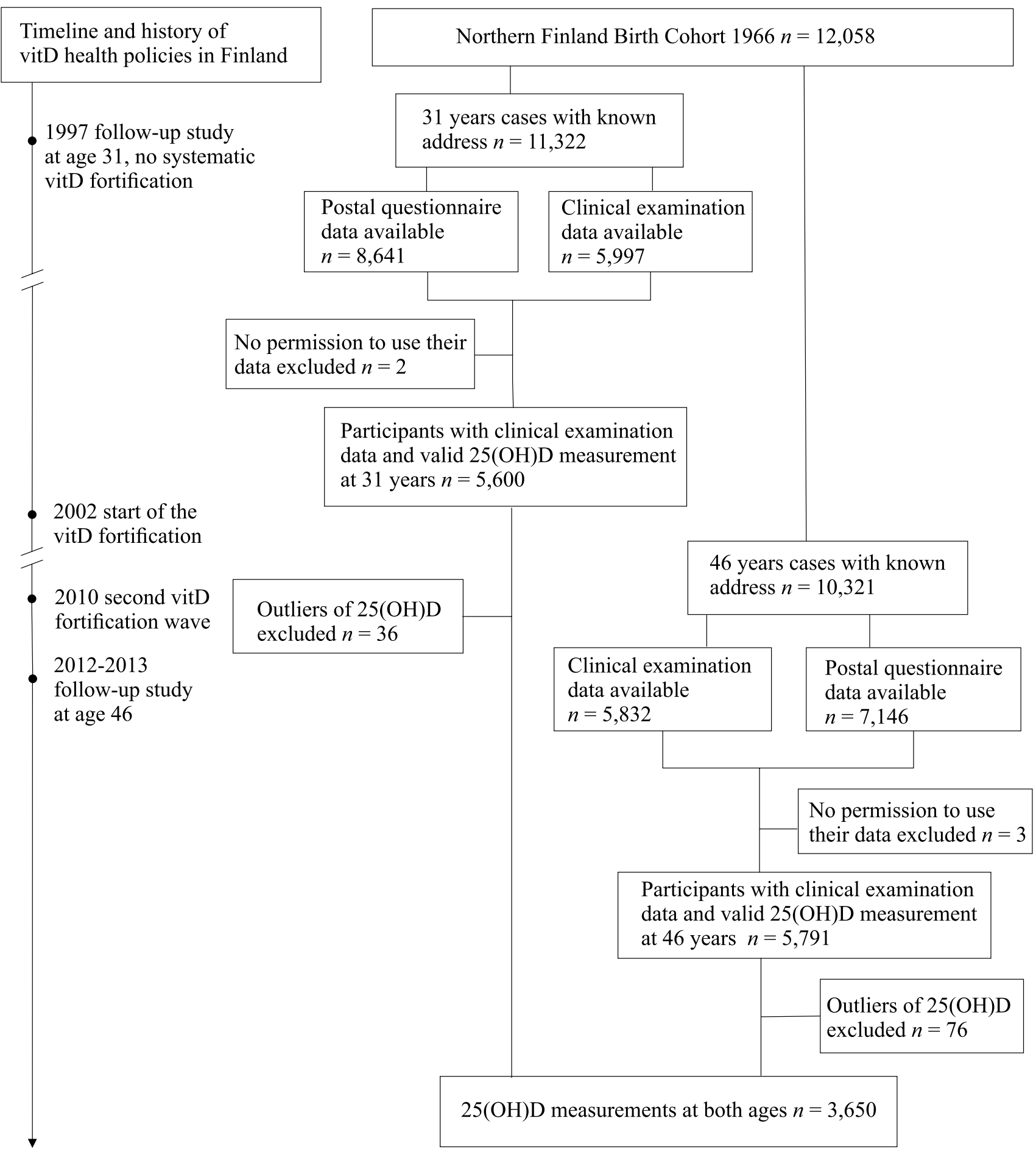

Fig. 1 Flowchart of the study population $(n=3650)$ of the Northern Finland Birth Cohort 1966 at the 31-year (1997) and 46-year (2012-2013) follow-ups, including the timelines and history of the start of vitamin D fortification

assay has been certified according to the Center for Disease Control and Prevention's Vitamin D StandardizationCertification Program [29]. An equation was calculated to convert the 31-year 25(OH)D concentrations to the Vitamin D Standardization Program-calibrated concentrations
[30]. The calibrated concentrations were used in the final analyses. At age 46 , the serum $25(\mathrm{OH}) \mathrm{D}$ concentrations were measured using the Architect i2000SR automatic analyzer (Abbott Diagnostics). The CV derived from the repeated quality-control samples included in the assay 
with the study samples were calculated. The CV for the internal control samples was $\leq 3.6 \%$ across the working range.

\section{Covariates}

The possible covariates for the study were selected according to the literature in the field, our own testing and other specific factors related to the present study [23, 31]. For ages 31 and 46 years, we had information regarding the participants' BMI, marital status, occupational and educational status, physical activity, smoking, alcohol consumption, season of blood sampling sample collection, and latitude of residence. In addition, for age 46 years, we had the information regarding VitD intake from diet and the use of VitD supplements.

During the clinical examinations at both timepoints, the participants' height $(\mathrm{cm})$ and weight $(\mathrm{kg})$ while wearing light clothing were measured by well-trained nurses. BMI $\left(\mathrm{kg} / \mathrm{m}^{2}\right)$ was calculated using height and weight [32]. The information from the postal questionnaires was used when the measured weight and height were missing [33]. The self-reported and clinically measured BMI were verified as providing similar results [33].

From the postal questionnaires: Marital status was categorized as married (including married and cohabiting) and unmarried (not cohabiting/married, divorced, widowed). Occupational status was categorized as upper-level employees, lower-level employees/entrepreneurs, manual workers/ farmers, and non-workers by current occupational status. Educational status was defined and categorized into three groups, namely, basic, secondary, and higher level, based on the information in the postal questionnaires. Physical activity was calculated based on the frequency and duration of leisure time activities [34] as metabolic equivalent of task (MET) scores in hours per week [34]. Smoking status was categorized as non-smokers, occasional/former smokers, and active smokers. Alcohol intake was calculated as g/day (d) based on the consumption of beer, wine, and spirits in 6 months prior to completing the questionnaire [35]. Alcohol intake was further categorized as abstainers $(0 \mathrm{~g} / \mathrm{d})$, lowrisk drinking ( $\leq 40 \mathrm{~g} / \mathrm{d}$ for males and $\leq 20 \mathrm{~g} / \mathrm{d}$ for females) and high-risk drinking ( $>40 \mathrm{~g} / \mathrm{d}$ for males and $>20 \mathrm{~g} / \mathrm{d}$ for females) [36].

Season of blood sampling was defined based on the date of the participants' clinical examinations at ages 31 and 46 . The seasons were categorized as low VitD season (November-May) and high VitD season (June-October) [37]. At age 46, blood samples were obtained throughout the year, but at age 31, clinical examinations were not performed in February and March due to the holiday season in Finland.

Latitude was defined by the participants' residence at the time of the follow-up studies in 1997 and 2012-2013.
This information was collected from the Finnish population register center and categorized as $60^{\circ} \mathrm{N}$ (Helsinki and other provinces of middle and southern Finland), $65^{\circ} \mathrm{N}$ (the city of Oulu), and $\geq 65^{\circ} \mathrm{N}$ (other northernmost provinces of Oulu and Lapland) [23].

The participants' dietary intake of VitD at the age of 46 was evaluated based on a food frequency questionnaire assessing frequency of food consumption during the preceding 6 months, as previously described in detail [38, 39]. Briefly, the National Food Composition Database in Finland, which is maintained by the National Institute for Health and Welfare [12], was used to evaluate VitD consumption from dairy products, spreadable fats, and fish.

- The consumption of dairy products was established from the question "How many glasses $(0.2 \mathrm{~L})$ do you usually drink/eat per day of: 1 . Milk, 2. Sour milk, 3 . Other dairy products (e.g., yoghurt, other fermented milk products, ice cream)?" All dairy products except cheese were estimated to contain $1 \mu \mathrm{g}$ of VitD per $100 \mathrm{~g}[12,17,38,40]$.

- The VitD content in fat spreads varies according to spread types: butter and organic butter contain $0 \mu \mathrm{g} / \mathrm{g}$ of VitD, vegetable oil spreads and plant-based sterol and stanol margarines $0.2 \mu \mathrm{g} / \mathrm{g}$, and vegetable oil mixtures $0.1 \mu \mathrm{g} / \mathrm{g}$. The consumption of fat spreads was established from the answers to the questions: "What type of bread spread do you usually use?" "How many times do you eat bread per day?" and "How much spread do you put on a slice of bread?"

- A serving of fish (approximately $150 \mathrm{~g}$ ) was estimated to contain $13.4 \mu \mathrm{g}$ of VitD based on information regarding the 10 most consumed fish from the Finnish National Food Composition Database [12]. If fish was eaten almost daily, the VitD dose was approximated to be $13.4 \mu \mathrm{g} / \mathrm{d}$; if twice a week, $3.8 \mu \mathrm{g} / \mathrm{d}$; and if once a week, $1.9 \mu \mathrm{g} / \mathrm{d}$. Less than that was estimated to be $0 \mu \mathrm{g}$ of VitD [12, 38].

We estimated the use of VitD supplements at the age of 46 using the following information from the postal questionnaires:

- The name of the product,

- The VitD content of the product informed by the participant, or if missing, by the product manufacturer,

- The number of tablets per day,

- The frequency of supplementation; the frequency of supplementation was estimated as "regular use" if the participant answered that they used VitD daily or regularly. All other answers (every other day, twice a week, during dark time, etc.) were considered "irregular." 
We included all VitD-containing supplements, including multivitamins, calcium, and omega- 3 supplements. In cases where the VitD content was missing, it was estimated using the name of the product and the VitD content informed by the product manufacturer. The question regarding the use of vitamins, nutritional supplements, and medications was open-ended, missing information were classified as "nonusers". Participants who indicated the frequency of VitD supplementation were included even if the dose of the VitD supplement was missing $(n=76)$.

To control for the effect of different covariates on serum $25(\mathrm{OH}) \mathrm{D}$, we standardised the measures of serum $25(\mathrm{OH})$ $\mathrm{D}$ as $\mathrm{z}$-scores adjusting for sex, seasonal, geographical and technical variation (batch correction only for 31-year measurements). The z-scores were formed separately in the different combinations of the categories of the aforementioned variables. The resulting $\mathrm{z}$-scores were combined into one variable, and these $\mathrm{z}$-score variables for the 31 - and $46-$ year $25(\mathrm{OH}) \mathrm{D}$ concentrations were used in the regression analysis.

\section{Statistical analyses}

The normal distribution of the continuous variables was assessed visually using histograms with normality curves. To assess differences by VitD status groups and time, we used Pearson's Chi-square test for categorical variables, one-way analysis of variance for normally distributed continuous variables and Kruskal-Wallis test for the non-parametric continuous variables. To study the differences in VitD intake characteristics between the sexes, we used an independent samples $t$ test, Pearson's Chi-squared test, and the Mann-Whitney $U$ test.
To assess the effect of different covariates on $25(\mathrm{OH}) \mathrm{D}$, we performed a multivariable linear regression analysis with 46-year $25(\mathrm{OH}) \mathrm{D}$ z-score as the dependent variable and the intakes of fluid dairy products, fat spreads and fish, supplement use, BMI and 31-year 25(OH)D $z$ score as independent variables. We tested for marital status, physical activity, smoking, alcohol consumption, occupational and education variables and their relevant two-way interactions in the model, but no interaction was found, and their effects did not change the estimates of the other variables in the model. As a sensitivity analysis, we ran a similar regression analysis including the outlier data and an another with exclusion of females using oral contraceptives and hormonal replacement therapy (Online resource 2), since there is evidence for a difference in $25(\mathrm{OH}) \mathrm{D}$ among this group [23, 24].

The statistical analyses were performed using IBM SPSS Statistics for Windows, Version 25 (IBM Corp. Armonk, NY). Figure 1 was executed using CorelDRAW Graphics Suite 2019, Version 21.0.0.593 (Corel Corporation, Canada) and Figs. 2 and 3 using GraphPad Prism Version 8.0.1.244 (GraphPad Software, San Diego).

\section{Results}

\section{VitD status in NFBC1966}

The descriptive characteristics of the studied population at ages 31 (in 1997) and 46 (in 2012-2013) and the differences by VitD status group are shown in Table 1 . BMI decreased and physical activity increased towards the highest VitD status group, and the magnitude of the difference between the lowest and the highest VitD status
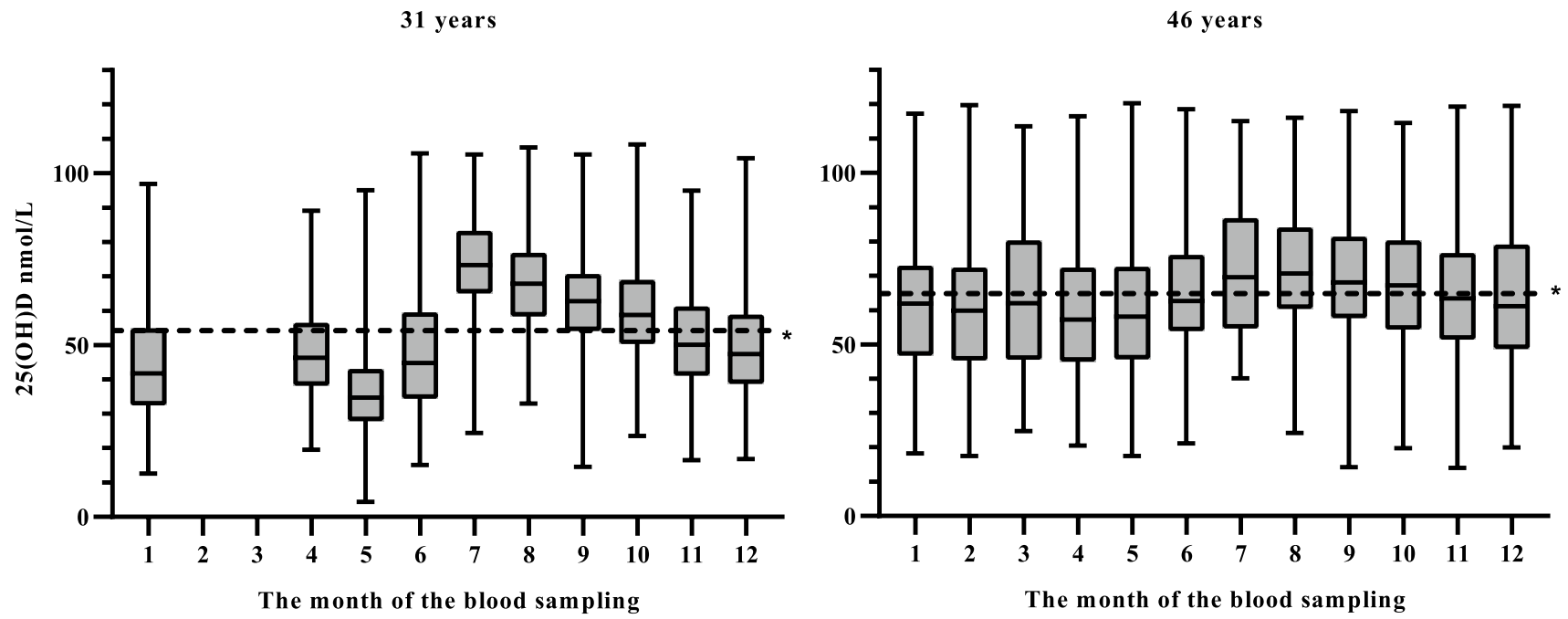

Fig. 2 Monthly variations in serum 25(OH)D concentrations at ages 31 (1997) and 46 years (2012-2013) in the Northern Finland Birth Cohort 1966. *Dashed line showing the mean of all the $25(\mathrm{OH}) \mathrm{D}$ measurements at 31 and 46 years 


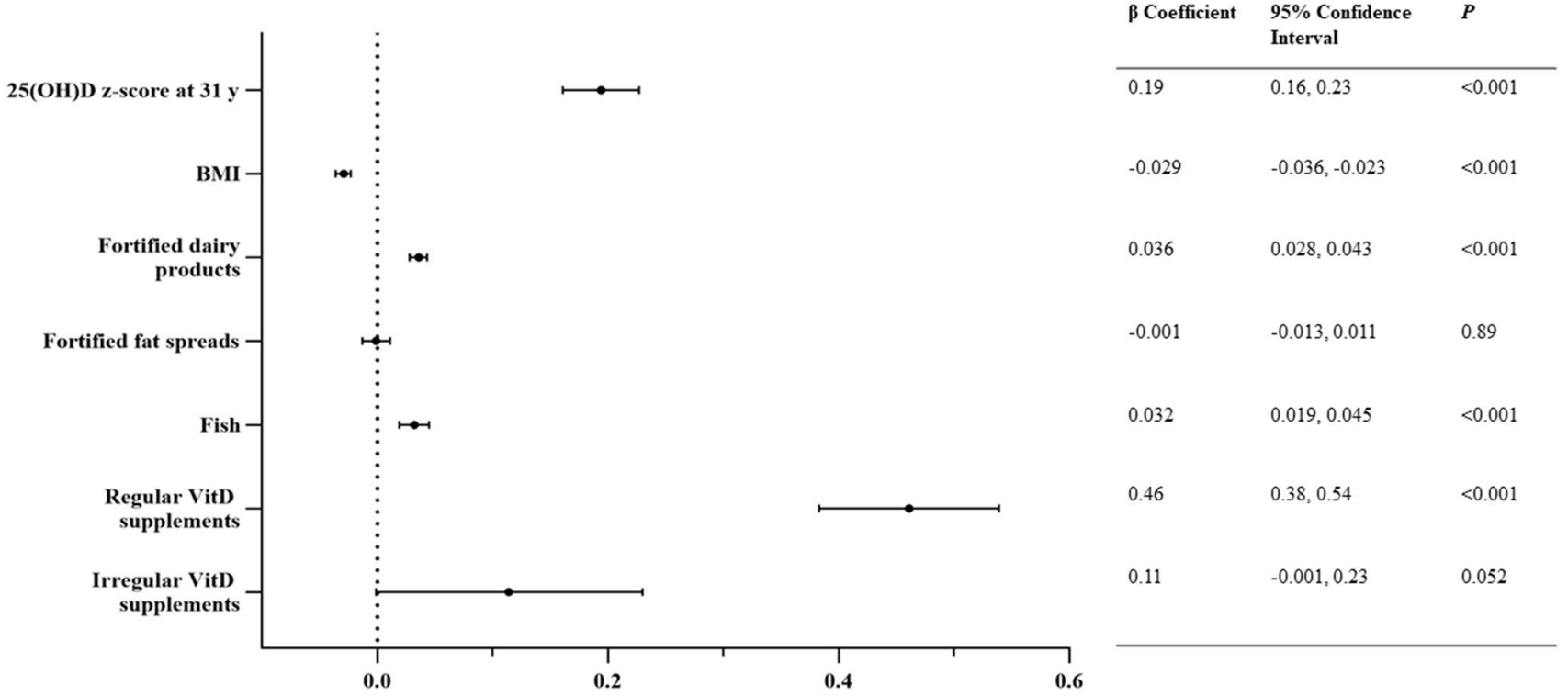

Fig. 3 Results of the multivariable linear regression analyses of the 25(OH)D $z$ score with different exposures at age 46 (2012-2013) in the Northern Finland Birth Cohort 1966. For VitD supplementation, no VitD supplementation was used as a reference category

groups was larger at 46 years compared with 31 years. A higher proportion of measurements was taken during the high VitD season at 31 years, whereas it was the opposite at 46 years: a higher proportion of measurements were taken during the low VitD season.

The VitD status of the studied population (Table 2) showed that, on average, serum $25(\mathrm{OH}) \mathrm{D}$ concentrations increased by $10.6 \mathrm{nmol} / \mathrm{L}$ (SD 24.4) during the follow-up. The prevalence of $25(\mathrm{OH}) \mathrm{D}<50 \mathrm{nmol} / \mathrm{L}$ decreased nearly by half ( $42.7 \%$ at age 31 and $23.5 \%$ at age 46$)$. In addition, $25(\mathrm{OH}) \mathrm{D}>75 \mathrm{nmol} / \mathrm{L}$ doubled from 31 to 46 years. Those having serum $25(\mathrm{OH}) \mathrm{D}<30 \mathrm{nmol} / \mathrm{L}$ at 31 years, had the highest increase in $25(\mathrm{OH}) \mathrm{D}$ in the follow-up compared with the other VitD status groups: the change in serum $25(\mathrm{OH}) \mathrm{D}$ was $34.9,21.9,4.5,-13.8 \mathrm{nmol} / \mathrm{L}$ from the lowest to the highest VitD status group $(<30,30-50,50-75$, and $>75 \mathrm{nmol} / \mathrm{L}$, respectively).

Figure 2 demonstrates the monthly variations in serum $25(\mathrm{OH}) \mathrm{D}$ concentrations at both timepoints. The mean seasonal difference in the serum $25(\mathrm{OH}) \mathrm{D}$ concentrations between the summer and winter months was $17.2 \mathrm{nmol} / \mathrm{L}$ at age 31: the mean in the winter months was $43.6 \mathrm{nmol} / \mathrm{L}$ (SD 15.4) and in the summer months 60.8 (SD 17.2). At age 46 , this difference was reduced to $8.3 \mathrm{nmol} / \mathrm{L}$ : the mean in winter was $61.7 \mathrm{nmol} / \mathrm{L}$ (SD 19.7) and in summer, $69.0 \mathrm{nmol} / \mathrm{L}$ (SD 18.0). When comparing the 31- and 46-year data, we observed that the serum $25(\mathrm{OH}) \mathrm{D}$ concentrations increased by $41.6 \%$ in the winter months and $13.4 \%$ in the summer months during the 15 -year follow-up period.

\section{Intake of VitD from diet and supplementation}

Table 3 shows the contribution of dietary intake of VitD and the use of VitD supplements to serum 25(OH)D concentrations at age 46 . The total VitD intake from diet, estimated from fortified dairy products, fortified fat spreads, and fish was on average $11.0 \mu \mathrm{g} / \mathrm{d}$ (SD 5.8), of which $6.0 \mu \mathrm{g} / \mathrm{d}$ came from fortified dairy products, $4.3 \mu \mathrm{g} / \mathrm{d}$ from fortified fat spreads, and $2.0 \mu \mathrm{g} / \mathrm{d}$ from fish. As a supplementary analysis, we tested for the differences in the intake of VitD between the sexes. The results are shown in the Online Resource 4. The estimated intake of VitD from the diet was higher in males than in females $(12.3 \mu \mathrm{g}$ vs. $10.1 \mu \mathrm{g}$, respectively, $P<0.001$; Online Resource 4).

When comparing the intake of dietary VitD at 46 years, we observed differences by VitD status group: the intake of VitD from total nutrition $(P<0.001)$, fortified dairy products $(P<0.001)$, and fish $(P<0.027)$ was lowering towards the lowest VitD status group. There was no significant difference in VitD intake from fortified fat spreads between the VitD status groups. When the intakes of VitD from fortified dairy products and fat spreads were analyzed as quartiles, we observed a dose-response relationship between serum 25(OH)D concentrations and fortified dairy intake quartiles $(60.4,63.2,65.0$, and $68.8 \mathrm{nmol} / \mathrm{L}$, $P<0.001$, from the lowest to the highest quartile). Regarding the fortified fat spread intake quartiles, no evidence for a significant difference in VitD status was observed (66.1, $63.8,64.0$, and $64.9 \mathrm{nmol} / \mathrm{L}, P=0.14$, respectively). 


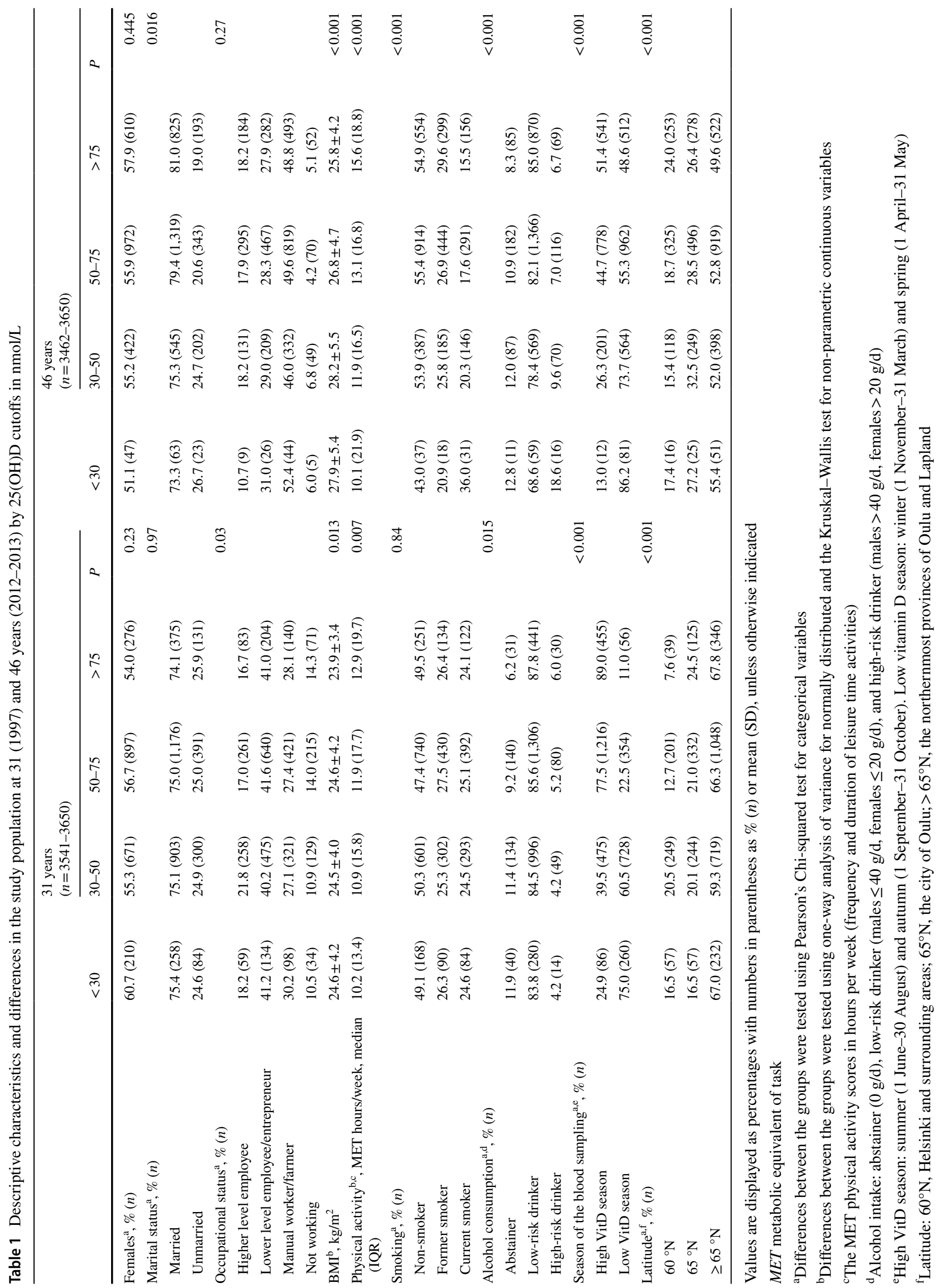


Table 2 25(OH)D status of the study population

\begin{tabular}{lll}
\hline & 31 years $(n=3650)$ & 46 years $(n=3650)$ \\
\hline $\begin{array}{l}\text { 25(OH)D, nmol/L } \\
\text { Prevalence, } \%(n)\end{array}$ & $54.2 \pm 18.5$ & $64.8 \pm 19.4$ \\
$<30 \mathrm{nmol} / \mathrm{L}$ & $9.5(346)$ & $2.5(92)$ \\
$30-50 \mathrm{nmol} / \mathrm{L}$ & $33.2(1,213)$ & $21.0(765)$ \\
$50-75 \mathrm{nmol} / \mathrm{L}$ & $43.3(1,581)$ & $47.7(1,740)$ \\
$>75 \mathrm{nmol} / \mathrm{L}$ & $14.0(510)$ & $28.8(1,053)$ \\
\hline
\end{tabular}

Values are displayed as mean (SD) or percentages with numbers in parentheses as \% $(n)$

25(OH)D 25-hydroxyvitamin D

VitD supplements were used by a quarter of the study population (25.8\%) at age 46 (Table 3). Among this population, $71.5 \%$ used supplements regularly and $28.5 \%$ irregularly. Regular supplementation use was more common in the $>75 \mathrm{nmol} / \mathrm{L}(29.4 \%)$ and the $50-75 \mathrm{nmol} / \mathrm{L}(16.6 \%)$ groups compared with VitD status groups with $25(\mathrm{OH})$ $\mathrm{D}<50 \mathrm{nmol} / \mathrm{L}(12.8 \%, P<0.001)$. The frequency of regular use of VitD supplements in females was higher compared with males ( $24.5 \%$ vs. $10.8 \%, P<0.001$; Online Resource 4). The median dose of VitD supplementation in the study population at 46 years was $10.0 \mu \mathrm{g}$ (IQR 12.5). The dose of VitD supplementation increased by the VitD status group (Table 3).

\section{Predictors of VitD status at 46 years}

Figure 3 shows the results of the multivariable linear regression model, which was conducted to examine the independent association of multiple predictors of VitD status at 46 years. The $25(\mathrm{OH}) \mathrm{D}$ z-score (standardized for sex, season and latitude) at 46 years was positively predicted by the intake of fortified dairy products, fish intake, and regular use of VitD supplements. The reported intake of fortified fat spreads was not associated with the 46-year $25(\mathrm{OH}) \mathrm{D}$ $\mathrm{z}$-score. The 46-year $25(\mathrm{OH}) \mathrm{D} z$ score was negatively associated with BMI, while the association with the 31-year $25(\mathrm{OH}) \mathrm{D} z$ score was positive. The coefficient of determination $\left(R^{2}\right)$ for the model was 0.16 .

\section{Discussion}

The present study represents one of the largest follow-up studies on VitD status from a longitudinal birth cohort and describes the effect of a national health policy among a middle-aged general population. According to our results, the population's mean serum $25(\mathrm{OH}) \mathrm{D}$ concentration was improved by $10.6 \mathrm{nmol} / \mathrm{L}$ (SD 24.4) at 46 years (1997) compared to 31 years (2012-2013), likely reflecting the initiation of the food fortification policy in Finland.

We observed that the prevalence of serum 25(OH)D concentrations $<50 \mathrm{nmol} / \mathrm{L}$ decreased from 42.7 to $23.5 \%$ and $<30 \mathrm{nmol} / \mathrm{L}$ (indicating vitD deficiency [14]) from $9.5 \%$ to $2.5 \%$ during the 15 years of follow-up. The highest increase in serum $25(\mathrm{OH}) \mathrm{D}$ was found among those participants having the lowest VitD status at baseline, which is reflecting the effectiveness of the food fortification program. In addition, seasonal differences in mean $25(\mathrm{OH}) \mathrm{D}$ concentrations were reduced at the 46-year follow-up, and most of the study population maintained $25(\mathrm{OH}) \mathrm{D}$ concentration $\geq 50 \mathrm{nmol} / \mathrm{L}$ throughout the year. This follows the trend reported in a Finnish study based on Health 2000 and 2011 (H2000-2011) samples [18], which reported a decrease in the prevalence of $25(\mathrm{OH}) \mathrm{D}<50 \mathrm{nmol} / \mathrm{L}$ from

Table 3 Vitamin D intake from diet and the use of VitD supplements at 46 years and the differences by $25(\mathrm{OH}) \mathrm{D}$ cutoffs in $\mathrm{nmol} / \mathrm{L}$

\begin{tabular}{|c|c|c|c|c|c|c|c|}
\hline & $n$ & Mean \pm SD & $<30$ & $30-50$ & $50-75$ & $>75$ & $P$ \\
\hline Total nutrition $^{\mathrm{a}}, \mu \mathrm{g} / \mathrm{d}$ & 3638 & $11.0 \pm 5.8$ & $8.9 \pm 18.7$ & $9.6 \pm 5.1$ & $11.4 \pm 6.1$ & $11.6 \pm 5.8$ & $<0.001$ \\
\hline Fortified dairy products ${ }^{\mathrm{a}}, \mu \mathrm{g} / \mathrm{d}$ & 3555 & $6.0 \pm 4.1$ & $4.3 \pm 3.9$ & $5.0 \pm 3.4$ & $6.3 \pm 4.4$ & $6.6 \pm 4.0$ & $<0.001$ \\
\hline Fortified fat spreads ${ }^{\mathrm{a}}, \mu \mathrm{g} / \mathrm{d}$ & 2766 & $4.3 \pm 2.6$ & $4.4 \pm 2.7$ & $4.2 \pm 2.5$ & $4.4 \pm 2.8$ & $4.1 \pm 2.5$ & 0.054 \\
\hline Fish $^{\mathrm{a}}, \mu \mathrm{g} / \mathrm{d}$ & 3384 & $2.0 \pm 2.4$ & $1.4 \pm 2.0$ & $1.8 \pm 2.2$ & $2.0 \pm 2.4$ & $2.2 \pm 2.5$ & 0.001 \\
\hline Use of supplements ${ }^{\mathrm{b}}, \%(n)$ & 3650 & & & & & & $<0.001$ \\
\hline Regular & & $18.5(672)$ & $3.3(3)$ & $9.5(73)$ & $16.5(288)$ & $29.4(310)$ & \\
\hline Irregular & & $7.3(268)$ & $4.3(4)$ & $5.3(40)$ & $7.8(135)$ & $8.5(89)$ & \\
\hline No & & $74.2(2,708)$ & $92.4(85)$ & $85.2(652)$ & $75.7(1,317)$ & $62.1(654)$ & \\
\hline $\begin{array}{l}\text { Supplementation dose } \mathrm{a}^{\mathrm{a}}, \mu \mathrm{g} / \mathrm{d}, \\
\text { median (IQR) }\end{array}$ & 866 & $10.0(12.5)$ & $4.4(17.5)$ & $10.0(10)$ & $10.0(12.5)$ & $16.3(20.0)$ & $<0.001$ \\
\hline
\end{tabular}

Values are displayed as mean (SD) or percentages with numbers in parentheses as \% (n), unless otherwise indicated

${ }^{a}$ Differences between the groups were tested using one-way analysis of variance for normally distributed and Kruskal-Wallis test for the nonparametric continuous variables

${ }^{\mathrm{b}}$ Differences between the groups were tested using Pearson's Chi-squared test for categorical variables 
55.7 to $9.1 \%$. The difference in the prevalence of serum $25(\mathrm{OH}) \mathrm{D}<50 \mathrm{nmol} / \mathrm{L}$ between these studies might be partly explained by a higher proportion of sampling conducted during the summer months in the H2011 survey compared with the NFBC1966 study, as well as with a higher percentage of the population from Northern Finland in our sample.

In contrast to the observations in Finland, another recent study from Northern Sweden found no clear time trend in serum 25(OH)D concentrations from 1986 to 2014 [19]. Relatively stable longitudinal 25(OH)D concentrations have also been described from Norway [20], the Longitudinal Aging Study Amsterdam [41], and three studies from the US [42-44], although notable seasonal variations were reported [20,41]. To compare with other Nordic countries, the fortification policies have not been as systematic as in Finland, which might be explaining the differences in the change of VitD status (Online resource 1).

In addition to the national food fortification policy in Finland, many health information campaigns were communicating effectively about the beneficial effects of VitD. Nowadays, many people adhere to recommendations regarding VitD supplementation. In our sample, VitD supplementation was used by $26 \%$ of the population at 46 years, whereas the Finnish H2000-2011 study reported an increase from 11 to $41 \%$ [18]. Regular supplementation use had a significant effect on serum $25(\mathrm{OH}) \mathrm{D}$ concentration compared to no supplementation (an increase of 0.5 SD in regular supplement users vs. no supplement). It is noteworthy that in our questionnaire, the use of VitD supplementation was queried via an open-ended question ["In this section, write down the names, strengths and dosages of the medicines you are using. Do you use these medicines regularly or on a needs basis, and for which purpose? (on-the-shelf drugs, prescription drugs, ointments, vitamins and food supplements)"], which may have led to an underestimation of supplementation consumption. In addition, in the H2011 survey, the mean age of the population was higher (56 years), which may explain the difference we reported. Indeed, the use of supplements is usually more common in older age groups [18]. Our study population was mainly located in Northern Finland, whereas in the H2000-2011 study, the subjects were mainly from Southern Finland, suggesting possible differences in behavior and habits by region.

The mean intake of VitD from diet in our study population was $11.0 \mu \mathrm{g} / \mathrm{d}$, which exceeds the Finnish and Nordic nutrition recommendations $(10 \mu \mathrm{g} / \mathrm{d})[14,15]$. This is a sign of a successful fortification policy. Sweden and Norway are also following fortification policies, but the amount of VitD added has been lower compared to Finland, and the VitD intake was lower in these countries in 2010-2011 (Online resource 1) [14]. In our study, dietary VitD was mainly obtained from milk products. We observed a dose-response effect in serum $25(\mathrm{OH}) \mathrm{D}$ concentrations across increasing milk intake quartiles. This finding is supported by earlier evidence [13]. A recent narrative review reported a positive association between the consumption of VitD fortified milk and VitD status [13]. In contrast, VitD from fortified fat spreads was not associated with serum $25(\mathrm{OH}) \mathrm{D}$ concentrations in our study, which was consistent with the H2000-2011 study [18].

The different effect of fortified milk products and fat spreads on serum $25(\mathrm{OH}) \mathrm{D}$ concentrations may be the result of health and lifestyle factors related to the use of these food items. In general, it has been suggested that the consumption of dairy products is associated with an overall healthy diet and a decreased risk for several diseases, especially cardiovascular diseases, type 2 diabetes, and metabolic syndrome $[45,46]$. On the other hand, the consumption of fat spreads may be associated with unhealthier lifestyle and obesity [47], and our finding may reflect this difference. It can also be speculated that the difference arose, because the bioavailability of VitD is different between fortified milk and fat spreads $[48,49]$. However, based on our study findings, we could dispute whether the current strategy of adding VitD in fat spreads is beneficial in increasing serum $25(\mathrm{OH})$ $\mathrm{D}$ concentrations in the general population. To the best of our knowledge, the current literature does not address this question.

In line with our study findings, there was no evidence in terms of a sex difference in VitD status according to a systematic review of observational studies published worldwide [50]. However, we found that males gained more VitD from their diet than females (12.3 vs. $10.1 \mu \mathrm{g}$, respectively), whereas females reported higher VitD supplementation than males ( $24.5 \%$ vs. $10.8 \%$, respectively). This result was consistent with those of previous studies [15, 18, 51]. In general, energy intake from diet is higher in males [52], but it is noteworthy to acknowledge the difference in supplementation use.

We found the study population's 31-year 25(OH)D to be predictive of their $25(\mathrm{OH}) \mathrm{D}$ at 46 years. To our knowledge, only one study has previously observed a similar finding in an adult population [20]. In our multivariable linear regression model, we were able to adjust for several confounders, including diet and supplementation. Our result may indicate that individual factors (e.g., sociodemographic, lifestyle, or genetics [53]) have an important role to play in VitD status in addition to nutrition and other VitD sources. This was shown in our findings as well: BMI, physical activity, smoking, and alcohol consumption differed between the VitD status groups, which is in line with previous knowledge from longitudinal studies [23, 31, 54, 55]. Individual biological pathways are also possibly linked to VitD status: absorption, liver and kidney function, chronic diseases, and medications. Future research is warranted to clarify these pathways and their role in individual VitD status. 
Our study had multiple strengths. The study was based on a large general population-based cohort with a high participation rate and included a population from the same genetic, ethnic, and cultural backgrounds. As we were able to focus on specific age groups, possible confounding by age was accounted for [50]. Our findings also serve as important information for future studies investigating the effect of VitD food fortification on the risk for chronic diseases. In our analyses, we were able to control for several potential confounding factors that are known to be associated with serum 25(OH)D (e.g., BMI, season, and latitude) [23]. In addition, using a comprehensive questionnaire at 46 years, we were able to obtain information about the participants' nutrition, and supplementation use.

One of the limitations of our study was that to respect of the timing of our study to assess the effect of fortification, it would have been more informative to use baseline serum 25(OH)D measurements before each wave of fortification. In addition, we had only one measurement per timepoint. A further limitation was that we did not have precise information about the participants' supplementation use at age 31 . Our supplementation data at 46 years was not concurrent with the nationwide report, but VitD supplementation was positively associated with serum $25(\mathrm{OH}) \mathrm{D}$ concentrations, so we consider the supplementation data reliable.

In conclusion, our results indicate a positive impact from the public health action on reducing the prevalence of serum $25(\mathrm{OH}) \mathrm{D}<30 \mathrm{nmol} / \mathrm{L}$ and $50 \mathrm{nmol} / \mathrm{L}$, and seasonal variations in VitD status among middle-aged adults in Finland. In addition to food fortification, regular VitD supplementation had an important effect on $25(\mathrm{OH}) \mathrm{D}$, an increase of 0.5 SD compared to no supplementation. Although the fortification policy has influenced the entire population, we observed that the 31 -year $25(\mathrm{OH}) \mathrm{D}$ concentrations in 1997 independently associated with serum $25(\mathrm{OH}) \mathrm{D}$ concentrations 15 years later in 2012-2013, which might be explained by behavioural or genetic factors. Our current study findings raise the question how to best locate the individuals who are at risk for serum 25(OH)D concentrations below $50 \mathrm{nmol} / \mathrm{L}$ and how to promote a further improvement of VitD status at population level.

Supplementary Information The online version contains supplementary material available at https://doi.org/10.1007/s00394-021-02606-z.

Acknowledgements The authors thank Katri Puukka, Petteri Oura, Marjukka Nurkkala, Anu Outinen-Tuuponen, MarjaLeena Kytökangas, and Heljä-Marja Surcel who contributed to this study. The authors thank all the participants of the NFBC1966 and the NFBC1966 team. The authors do not have the authority to make data public.

Author contributions The authors' contributions were as follows: HI and JL designed the study. HI, JL and PP performed the statistical analysis. HI and JL wrote the first draft of the manuscript and are shared first authors. All authors commented on previous versions of the manuscript. SS and MOmi co-supervised the paper and share the final authorship. M-RJ partially funded the study. All the authors critically read, reviewed, revised and approved the final manuscript.

Funding Open access funding provided by University of Oulu including Oulu University Hospital. Maarit Niinimäki, Marja Ojaniemi: University Hospital of Oulu and PEDEGO Research Unit, University of Oulu Research Funds. Terhi Piltonen: The Academy of Finland, the Sigrid Jusélius Foundation. Johanna Lumme: Päivikki and Sakari Sohlberg Foundation and the Health and Biosciences Doctoral Programme, HBS-DP (UniOGS, University of Oulu). Saranya Palaniswamy: Yrjö Jahnsson Foundation, Päivikki and Sakari Sohlberg Foundation and H2020-643774 iHealth-T2D, H2020-825762 EDCMET. Jussi Seppälä: South Carelia Social and Healthcare District. Sylvain Sebert, Helmi Ikonen and Marjo-Riitta Järvelin: H2020-633595 DynaHEALTH, H2020733206 LifeCycle, H2020-824989 EUCANCONNECT, H2020873749 LongITools, H2020-848158 EarlyCause, the JPI HDHL, PREcisE project, ZonMw the Netherlands no. P75416. Marjo-Riitta Järvelin: Academy of Finland grant numbers 24300796, 24302031, 285547 (EGEA); H2020-643774 iHealth-T2D, H2020-825762 EDCMET and Medical Research Council Biotechnology and Biological Sciences Research Council PREcisE (Nutrition \& Epigenome, grant reference: MR/S03658X/1), The Joint Programming Initiative a Healthy Diet for a Healthy Life (JPI HDHL/EU-H2020); ERDF European Regional Development Fund (539/2010 A31592) Karl-Heinz Herzig: H2020-633595 DynaHEALTH and H2020-643774 iHealth-T2D, H2020-825762 EDCMET.

Availability of data and materials NFBC data are available from the University of Oulu, Infrastructure for Population Studies. Permission to use the data can be applied for research purposes via electronic material request portal. In the use of data, we follow the EU general data protection regulation (679/2016) and Finnish Data Protection Act. The use of personal data is based on cohort participant's written informed consent at his/her latest follow-up study, which may cause limitations to its use. Please, contact NFBC project center (NFBCprojectcenter@oulu.fi) and visit the cohort website (www.oulu.fi/nfbc) for more information.

Code availability Code for the study is available from the corresponding author.

\section{Declarations}

Conflict of interest The authors declare that they have no conflict of interest. The funders had no role in the design of the study, the collection, analysis, interpretation of the data, or the preparation of the manuscript.

Ethical approval The study was approved by the ethical committee of the Northern Ostrobothnia Hospital District and the University of Oulu. The procedures followed the 1964 Declaration of Helsinki and its later amendments.

Consent to participate Study protocol has been accepted by the local ethics committee. All participants have given written informed consent. It is not possible to identify the study participants.

Consent for publication All authors have given explicit consent to submit the article to the European Journal of Nutrition. Consent for publication has been granted from the NFBC project center. 
Open Access This article is licensed under a Creative Commons Attribution 4.0 International License, which permits use, sharing, adaptation, distribution and reproduction in any medium or format, as long as you give appropriate credit to the original author(s) and the source, provide a link to the Creative Commons licence, and indicate if changes were made. The images or other third party material in this article are included in the article's Creative Commons licence, unless indicated otherwise in a credit line to the material. If material is not included in the article's Creative Commons licence and your intended use is not permitted by statutory regulation or exceeds the permitted use, you will need to obtain permission directly from the copyright holder. To view a copy of this licence, visit http://creativecommons.org/licenses/by/4.0/.

\section{References}

1. Lips P, Eekhoff M, van Schoor N et al (2017) Vitamin D and type 2 diabetes. J Steroid Biochem Mol Biol 173:280-285. https://doi.org/10.1016/j.jsbmb.2016.11.021

2. Wang L, Song Y, Manson JE et al (2012) Circulating 25-Hydroxy-Vitamin D and risk of cardiovascular disease: a meta-analysis of prospective studies. Circ Cardiovasc Qual Outcomes 5:819-829

3. Pilz S, Verheyen N, Grübler MR et al (2016) Vitamin D and cardiovascular disease prevention. Nat Rev Cardiol 13:404-417. https://doi.org/10.1038/nrcardio.2016.73

4. Antico A, Tampoia M, Tozzoli R, Bizzaro N (2012) Can supplementation with vitamin $\mathrm{D}$ reduce the risk or modify the course of autoimmune diseases? A systematic review of the literature. Autoimmun Rev 12:127-136. https://doi.org/10.1016/j.autrev. 2012.07.007

5. Mondul AM, Weinstein SJ, Layne TM, Albanes D (2017) Vitamin D and cancer risk and mortality: state of the science, gaps, and challenges. Epidemiol Rev 39:28-48. https://doi.org/10. 1093/epirev/mxx005

6. Anglin RES, Samaan Z, Walter SD, Sarah DM (2013) Vitamin $D$ deficiency and depression in adults: systematic review and meta-analysis. Br J Psychiatry 202:100-107. https://doi.org/10. 1192/bjp.bp.111.106666

7. Wacker M, Holick MF (2013) Sunlight and vitamin D: a global perspective for health. Dermatoendocrinol 5:51-108. https:// doi.org/10.4161/derm.24494

8. Hossein-Nezhad A, Holick MF (2013) Vitamin D for health: a global perspective. Mayo Clin Proc 88:720-755. https://doi.org/ 10.1016/j.mayocp.2013.05.011

9. Gaksch M, Jorde R, Grimnes G et al (2017) Vitamin D and mortality: individual participant data meta-analysis of standardized 25-hydroxyvitamin D in 26916 individuals from a European consortium. PLoS ONE 12:e0170791. https://doi.org/10.1371/ journal.pone.0170791

10. Huotari A, Herzig KH (2008) Vitamin D and living in northern latitudes: an endemic risk area for vitamin D deficiency. Int $\mathbf{J}$ Circumpolar Health 67:164-178. https://doi.org/10.3402/ijch. v67i2-3.18258

11. Leary PF, Zamfirova I, Au J, McCracken WH (2017) Effect of latitude on vitamin D levels. J Am Osteopath Assoc 117:433439. https://doi.org/10.7556/jaoa.2017.089

12. National Institute for Health and Welfare, Public Health Promotion Unit (2019) Fineli. Finnish food composition database. Release 20. Helsinki 2019. https://www.fineli.fi/. Accessed 14 Nov 2019

13. Itkonen S, Erkkola M, Lamberg-Allardt C (2018) Vitamin D fortification of fluid milk products and their contribution to vitamin D intake and vitamin D status in observational studies-a review. Nutrients 10:1054. https://doi.org/10.3390/nu10081054
14. Itkonen ST, Andersen R, Björk AK et al (2020) Vitamin D status and current policies to achieve adequate vitamin $\mathrm{D}$ intake in the Nordic countries. Scand J Public Health. https://doi.org/10. $1177 / 1403494819896878$

15. Raulio S, Erlund I, Männistö S et al (2017) Successful nutrition policy: improvement of vitamin D intake and status in Finnish adults over the last decade. Eur J Public Health 27:268-273. https://doi.org/10.1093/eurpub/ckw154

16. Ministry of Social Affairs and Health (2006) Follow-up study on the vitamin D status in the Finnish population 2002 and 2004. Reports of the Ministry of Social Affairs and Health 2006:9(2/26/2014). https://ec.europa.eu/food/system/files/201610/labelling_nutrition-supplements-responses-finland_annex3_ en.pdf/. Accessed 24 Apr 2020

17. Finnish Food Authority (2014) Special instructions and restrictions: Vitamin D supplementation. https://www.ruokavirasto. fi/en/themes/healthy-diet/nutrition-and-food-recommendations/ special-instructions-and-restrictions/. Accessed 24 Apr 2020

18. Jääskeläinen T, Itkonen ST, Lundqvist A et al (2017) The positive impact of general vitamin D food fortification policy on vitamin D status in a representative adult Finnish population: evidence from an 11-y follow-up based on standardized 25-hydroxyvitamin D data. Am J Clin Nutr 105:1512-1520. https://doi.org/10.3945/ ajen.116.151415

19. Summerhays E, Eliasson M, Lundqvist R et al (2019) Time trends of vitamin D concentrations in northern Sweden between 1986 and 2014: a population-based cross-sectional study. Eur J Nutr. https://doi.org/10.1007/s00394-019-02142-x

20. Jorde R, Sneve M, Hutchinson M et al (2010) Tracking of serum 25-Hydroxyvitamin D levels during 14 years in a populationbased study and during 12 months in an intervention study. Am J Epidemiol 171:903-908. https://doi.org/10.1093/aje/kwq005

21. Rantakallio P (1988) The longitudinal study of the northern Finland birth cohort of 1966. Paediatr Perinat Epidemiol 2:59-88. https://doi.org/10.1111/j.1365-3016.1988.tb00180.x

22. NFBC1966 and NFBC1986 (2020) Northern Finland Cohorts. https://www.oulu.fi/nfbc/node/44315. Accessed 27 Feb 2020

23. Palaniswamy S, Hyppönen E, Williams DM et al (2017) Potential determinants of vitamin D in Finnish adults: a cross-sectional study from the Northern Finland birth cohort 1966. BMJ Open 7:e013161. https://doi.org/10.1136/bmjopen-2016-013161

24. Lumme J, Sebert S, Pesonen P et al (2019) Vitamin D levels in women with polycystic ovary syndrome: a population-based study. Nutrients. https://doi.org/10.3390/nu11112831

25. SPSS (2019) Outliers. http://www.unige.ch/ses/sococ/cl/spss/ concepts/outliers.html. Accessed 8 Nov 2019

26. Holick MF, Binkley NC, Bischoff-Ferrari HA et al (2011) Evaluation, treatment, and prevention of vitamin $\mathrm{D}$ deficiency: an endocrine society clinical practice guideline. J Clin Endocrinol Metab 96:1911-1930. https://doi.org/10.1210/jc.2011-0385

27. Ross AC, Manson JE, Abrams SA et al (2011) The 2011 dietary reference intakes for calcium and vitamin $\mathrm{D}$ : what dietetics practitioners need to know. J Am Diet Assoc 111:524-527. https://doi. org/10.1016/j.jada.2011.01.004

28. Williams DM, Palaniswamy S, Sebert S et al (2016) 25-hydroxyvitamin $\mathrm{D}$ concentration and leukocyte telomere length in young adults: findings from the Northern Finland Birth Cohort 1966. Am J Epidemiol 183:191-198. https://doi.org/10.1093/aje/kwv203

29. Sempos CT, Durazo-Arvizu RA, Binkley N et al (2016) Developing vitamin D dietary guidelines and the lack of 25-hydroxyvitamin D assay standardization: the ever-present past. J Steroid Biochem Mol Biol 164:115-119. https://doi.org/10.1016/j.jsbmb. 2015.08.027

30. Durazo-Arvizu RA, Tian L, Brooks SPJ et al (2017) The Vitamin D standardization program (VDSP) manual for retrospective laboratory standardization of serum 25-hydroxyVitamin D data. 
J AOAC Int 100:1234-1243. https://doi.org/10.5740/jaoacint. 17-0196

31. Jääskeläinen T, Knekt P, Marniemi J et al (2013) Vitamin D status is associated with sociodemographic factors, lifestyle and metabolic health. Eur J Nutr 52:513-525. https://doi.org/10.1007/ s00394-012-0354-0

32. WHO (2019) Obesity and overweight. https://www.who.int/newsroom/fact-sheets/detail/obesity-and-overweight. Accessed 14 Nov 2019

33. Ollila MME, Piltonen T, Puukka K et al (2016) Weight gain and dyslipidemia in early adulthood associate with polycystic ovary syndrome: prospective cohort study. J Clin Endocrinol Metab 101:739-747. https://doi.org/10.1210/jc.2015-3543

34. Suija K, Timonen M, Suviola M et al (2013) The association between physical fitness and depressive symptoms among young adults: results of the Northern Finland 1966 birth cohort study. BMC Public Health 13:535. https://doi.org/10.1186/ 1471-2458-13-535

35. Vladimirov D, Niemelä S, Auvinen J et al (2016) Changes in alcohol use in relation to sociodemographic factors in early midlife. Scand J Public Health 44:249-257. https://doi.org/10.1177/14034 94815622088

36. WHO: Noncommunicable Diseases and Mental Health Cluster. Department of Mental Health and Substance Dependence (2000) International guide for monitoring alcohol consumption and related harm. https://apps.who.int/iris/bitstream/handle/10665/ 66529/WHO_MSD_MSB_00.4.pdf. Accessed 19 Mar 2020

37. Seasons in Finland (2019) Finnish Meteorological Institute. https://en.ilmatieteenlaitos.fi/seasons-in-finland. Accessed 13 Nov 2019

38. Oura P, Auvinen J, Paananen M et al (2019) Dairy- and supplement-based calcium intake in adulthood and vertebral dimensions in midlife: the Northern Finland Birth Cohort 1966 Study. Osteoporos Int 30:985-994. https://doi.org/10.1007/ s00198-019-04843-9

39. Laitinen J, Pietiläinen K, Wadsworth M et al (2004) Predictors of abdominal obesity among 31-y-old men and women born in Northern Finland in 1966. Eur J Clin Nutr 58:180-190. https:// doi.org/10.1038/sj.ejen.1601765

40. Nordic Council of Ministers (2014) Nordic nutrition recommendations 2012: integrating nutrition and physical activity, 5th edn. Denmark, Copenhagen

41. Van Schoor NM, Knol DL, Deeg DJH et al (2014) Longitudinal changes and seasonal variations in serum 25-hydroxyvitamin D levels in different age groups: results of the Longitudinal Aging Study Amsterdam. Osteoporos Int 25:1483-1491. https://doi.org/ 10.1007/s00198-014-2651-3

42. McKibben RA, Zhao D, Lutsey PL et al (2016) Factors associated with change in 25-hydroxyvitamin d levels over longitudinal follow-up in the aric study. J Clin Endocrinol Metab 101:33-43. https://doi.org/10.1210/jc.2015-1711
43. Mirfakhraee S, Ayers CR, McGuire DK, Maalouf NM (2017) Longitudinal changes in serum 25-hydroxyvitamin D in the Dallas Heart Study. Clin Endocrinol (Oxf) 87:242-248. https://doi.org/ 10.1111/cen.13374

44. Schleicher RL, Sternberg MR, Lacher DA et al (2016) The Vitamin D status of the US population from 1988 to 2010 using standardized serum concentrations of 25-hydroxyvitamin D shows recent modest increases. Am J Clin Nutr 104:454-461. https:// doi.org/10.3945/ajcn.115.127985

45. Crichton GE, Bogucki OE, Elias MF (2019) Dairy food intake, diet patterns, and health: findings from the Maine-Syracuse Longitudinal Study. Int Dairy J 91:64-70. https://doi.org/10.1016/j. idairyj.2018.12.009

46. Theodoratou E, Tzoulaki I, Zgaga L, Ioannidis JPA (2014) Vitamin D and multiple health outcomes: Umbrella review of systematic reviews and meta-analyses of observational studies and randomised trials. BMJ 348:g2035. https://doi.org/10.1136/bmj. g2035

47. Raatz SK, Conrad Z, Johnson LAK et al (2017) Relationship of the reported intakes of fat and fatty acids to body weight in US adults. Nutrients 9:438. https://doi.org/10.3390/nu9050438

48. Grossmann RE, Tangpricha V (2010) Evaluation of vehicle substances on vitamin D bioavailability: a systematic review. Mol Nutr Food Res 54:1055-1061. https://doi.org/10.1002/mnfr.20090 0578

49. Yang Z, Laillou A, Smith G et al (2013) A review of vitamin D fortification: implications for nutrition programming in Southeast Asia. Food Nutr Bull 34:S81-S89. https://doi.org/10.1177/15648 265130342S110

50. Hilger J, Friedel A, Herr R et al (2014) A systematic review of vitamin D status in populations worldwide. Br J Nutr 111:23-45. https://doi.org/10.1017/S0007114513001840

51. Pietinen P, Paturi M, Reinivuo H et al (2010) FINDIET 2007 Survey: energy and nutrient intakes. Public Health Nutr 13:920-924. https://doi.org/10.1017/S1368980010001102

52. Helldán A, Raulio S, Kosola M, et al (2013) The National FINDIET 2012 Survey. Reports of the National Institute for Health and Welfare (THL), THL

53. Wang TJ, Zhang F, Richards JB et al (2010) Common genetic determinants of vitamin D insufficiency: a genome-wide association study. Lancet 376:180-188. https://doi.org/10.1016/S01406736(10)60588-0

54. Pereira-Santos M, Costa PRF, Assis AMO et al (2015) Obesity and vitamin D deficiency: a systematic review and meta-analysis. Obes Rev 16:341-349. https://doi.org/10.1111/obr.12239

55. Mutt SJ, Jokelainen J, Sebert S et al (2019) Vitamin D status and components of metabolic syndrome in older subjects from Northern Finland (Latitude 65№rth). Nutrients 11:1229. https://doi. org/10.3390/nu11061229

\section{Authors and Affiliations}

\section{Helmi Ikonen ${ }^{1}$ - Johanna Lumme ${ }^{2,3,4} \cdot$ Jussi Seppälä ${ }^{1,5,13} \cdot$ Paula Pesonen $^{6} \cdot$ Terhi Piltonen $^{2,3,4}$. Marjo-Riitta Järvelin ${ }^{1,7,8,9} \cdot$ Karl-Heinz Herzig $^{3,10,11}$. Jouko Miettunen ${ }^{1,3} \cdot$ Maarit Niinimäki $^{2,3,4}$. Saranya Palaniswamy ${ }^{1,7} \cdot$ Sylvain Sebert ${ }^{1} \cdot$ Marja Ojaniemi $^{2,3,12}$}

1 Center for Life-Course Health Research, Faculty of Medicine, University of Oulu, 90014 Oulu, Finland

2 PEDEGO Research Unit, University of Oulu, 90014 Oulu, Finland
3 Medical Research Center Oulu, Oulu University Hospital and University of Oulu, 90014 Oulu, Finland

4 Department of Obstetrics and Gynecology, Oulu University Hospital, 90220 Oulu, Finland 
5 Department of Mental and Substance Use Disorders, South Carelia Social and Healthcare District, 53130 Lappeenranta, Finland

6 Infrastructure for Population Studies, Faculty of Medicine, University of Oulu, 90014 Oulu, Finland

7 Department of Epidemiology and Biostatistics, School of Public Health, Faculty of Medicine, St. Mary's Campus, Imperial College London, London W2 1PG, UK

8 Department of Life Sciences, College of Health and Life Sciences, Brunel University London, Kingston Lane, Uxbridge UB8 3PH, Middlesex, UK
9 Unit of Primary Care, Oulu University Hospital, 90220 Oulu, Finland

10 Institute of Biomedicine, Medical Research Center, University of Oulu, 90014 Oulu, Finland

11 Institute of Pediatrics, Department of Pediatric Gastroenterology and Metabolic Diseases, Poznan University of Medical Sciences, 60-572 Poznań, Poland

12 Department of Pediatrics and Adolescence, Oulu University Hospital, 90220 Oulu, Finland

13 Social Insurance Institute of Finland, 70110 Kuopio, Finland 